\title{
Panorama da contaminação ambiental por agrotóxicos no estado do mato grosso: risco para o abastecimento urbano
}

Panorama of environmental contamination by pesticides in the state of Mato Grosso: risk to urban supply

Panorama de contaminación ambiental por plaguicidas en el estado de Mato Grosso: riesgo de suministro urbano

Recebido: 04/01/2021 | Revisado: 05/01/2021 | Aceito: 08/01/2021 | Publicado: 09/01/2021

Cleidiane Moraes Novais

ORCID: https://orcid.org/0000-0002-5244-9243 Universidade do Estado do Mato Grosso, Brasil E-mail: cleidiane.novais@unemat.br

Tadeu Miranda de Queiroz ORCID: https://orcid.org/0000-0002-1959-7658 Universidade do Estado do Mato Grosso, Brasil E-mail: tdmqueiroz@unemat.br

Santino Seabra Júnior ORCID: https://orcid.org/0000-0002-4986-7778 Universidade do Estado do Mato Grosso, Brasil E-mail: santinoseabra@unemat.br

\begin{abstract}
Resumo
O estado do Mato Grosso tem a maior participação em vendas de agrotóxicos do Brasil, como consequência da expansão agrícola sofrida nos últimos anos. Fundamentando-se no risco de exposição humana a esses produtos pela ingestão de água contaminada, o presente artigo teve como objetivo identificar, analisar e descrever as contribuições científicas encontradas na literatura sobre o panorama da contaminação dos mananciais utilizados para abastecimento urbano mato-grossense, as metodologias analíticas para tratamento da contaminação e as políticas públicas voltadas para seu monitoramento. Constatou-se que apesar de existir legislações vigentes de controle da qualidade da água, há falhas no cumprimento e no monitoramento desses princípios ativos, motivo que é associado ao alto custo para o tratamento adequado, resultando assim, em diversos transtornos ambientais e sociais.
\end{abstract}

Palavras-chave: Pesticidas; Recursos hídricos; Saúde humana.

\begin{abstract}
The state of Mato Grosso has the largest share of sales of pesticides in the country, because of the agricultural expansion suffered in recent years. Based on the risk of human exposure to these products through the ingestion of contaminated water, this article aimed to identify, analyze and describe the scientific contributions found in the literature on the contamination of water sources used for urban supply in Mato Grosso, analytical methodologies for the treatment of contamination and the public policies focused on its monitoring. It was found that despite the existence of existing legislation to control water quality, there are flaws in the compliance and monitoring of these active principles, a reason that is associated with the high cost for proper treatment, resulting in various environmental and social disorders.
\end{abstract}

Keywords: Pesticides; Water resources; Human health.

\section{Resumen}

El estado de Mato Grosso tiene la mayor participación en las ventas de pesticidas en Brasil, como resultado de la expansión agrícola sufrida en los últimos años. Basado en el riesgo de exposición humana a estos productos a través de la ingestión de agua contaminada, este artículo tuvo como objetivo identificar, analizar y describir las contribuciones científicas encontradas en la literatura sobre el panorama de la contaminación de las fuentes de agua utilizadas para el suministro urbano en Mato Grosso, el Metodologías analíticas para el tratamiento de la contaminación y políticas públicas destinadas a monitorearla. Se descubrió que, a pesar de la existencia de las leyes actuales de control de calidad del agua, existen fallas en el cumplimiento y monitoreo de estos principios activos, una razón que está asociada con el alto costo del tratamiento adecuado, lo que resulta en varios trastornos ambientales y sociales.

Palabras clave: Pesticidas; Recursos hídricos; Salud humana. 


\section{Introdução}

Atualmente o estado do Mato Grosso é conhecido como celeiro do país, por conta da sua liderança, com uma participação de 26,8\%, na produção nacional de grãos (IBGE, 2018), sendo que o aumento progressivo na produtividade tem sido obtido através da "revolução verde", que segundo Gomes e Barizon (2014) baseia-se na intensiva utilização de plantas melhoradas geneticamente, além de utilização de insumos industriais, como fertilizantes e agrotóxicos, que por sua vez têm potencial contaminante.

Nesse sentido, Arias et al. (2007) citam que a aplicação desses insumos nos campos cultivados do estado podem impactar diretamente os corpos d'água, através da sua dispersão pela água da chuva e/ou da irrigação, assim como indiretamente por meio da percolação no solo, atingindo os lençóis freáticos. Assim sendo, a contaminação dos recursos hídricos pode provocar graves problemas à saúde pública mato-grossense, principalmente quando este recurso é utilizado para o abastecimento urbano, pois a ingestão diária de água e de alimentos contaminados por agrotóxicos pode provocar o acúmulo dessas substâncias no organismo humano, tendo potencial de causar graves doenças, como certos tipos de cânceres e distúrbios no sistema endócrino (Palma \& Lourencetti, 2011).

Além disso, as legislações nacionais vigentes de caracterização e classificação das águas não são suficientes para atender seus usos múltiplos possuindo deficiência na avaliação de qualidade (Arias, et al., 2007). Ademais, as metodologias tradicionais utilizadas no tratamento da água para consumo humano, acabam por desconsiderar análises mais complexas, capazes de detectar esses compostos químicos, tornando necessário aplicação de parâmetros de controle de qualidade mais eficientes e que ponderem as características da bacia hidrográfica correspondente, bem como tratamentos adequados.

Em consequência disso, Gomes e Barizon (2014) afirmam que mesmo existindo uma grande quantidade de dados físicos, químicos, ambientais e toxicológicos exigidos por órgãos reguladores de uso das moléculas de agrotóxicos, é necessário uma estruturação que garanta a sustentabilidade, através da avaliação e gerenciamento dos riscos da aplicação desses produtos, pois ainda restam muitas incertezas no que diz respeito aos impactos da utilização destas substâncias sobre a saúde humana e a proteção do meio ambiente.

Considerando o exposto, buscou-se reunir dados/informações bibliográficas com o propósito de responder a seguinte problemática: Qual a condição de contaminação dos corpos d'água mato-grossenses por resíduo de agrotóxico e quais as implicações para a saúde humana? É de conhecimento que a água potável tem fundamental importância para a manutenção da vida no planeta, pois nela contém dissolvidas grande parte das substâncias e elementos químicos indispensáveis, que participam dos processos metabólicos vitais para o desenvolvimento do ser humano (Brondi, 2000).

Portanto, o presente estudo teve como objetivo identificar, analisar e descrever as contribuições científicas encontradas na literatura sobre o panorama da contaminação por agrotóxicos de origem agrícola das águas dos mananciais utilizados para abastecimento urbano mato-grossense, avaliando: os principais resultados e impactos observados; os procedimentos considerados eficientes para diagnóstico e tratamento da contaminação e; as políticas públicas voltadas para a adequação das metodologias tradicionais utilizadas pelos municípios do estado.

\section{Metodologia}

Trata-se de uma pesquisa exploratória, mediante estudo de revisão bibliográfica com intuito de colocar em diálogo diferentes autores e dados, analisando-os qualitativamente (Pereira Filho, 2013). O estudo foi realizado nas bases de dados de órgãos governamentais (Instituto Brasileiro de Geografia e Estatística - IBGE, Sistema IBGE de Recuperação Automática SIDRA e Instituto Brasileiro do Meio Ambiente e dos Recursos Naturais Renováveis - IBAMA), no portal da Capes, teses e dissertações e Periódicos Capes (Scielo e Google Scholar) nos idiomas inglês e português, abrangendo teses, dissertações e artigos publicados entre os anos de 1996 e 2019. 
Os descritores para a busca foram: agrotóxicos abastecimento urbano MT, contaminação ambiental agrotóxicos, tratamento água contaminada agrotóxicos, análise cromatográfica agrotóxicos, políticas públicas agrotóxicos. No estudo foram incluídos aqueles que tratassem dos temas: análise de qualidade dos corpos d'água no estado do Mato Grosso, impactos sociais da contaminação da água para consumo humano, metodologias para tratamentos da água contaminada por agrotóxicos e políticas públicas voltadas para o tratamento adequado da água contaminada por agrotóxicos.

Somando-se todas as bases de dados, foram levantadas 85 referências. Após uma análise dos títulos, notou-se que alguns deles se repetiram nas diferentes bases e outros não preenchiam os critérios deste estudo. Foi realizada dessa forma, uma inspeção exploratória, resultando na seleção de 70 referências para a leitura do resumo, com exclusão dos que não tratavam do objeto de estudo, foram então selecionadas 53 que preenchiam os critérios inicialmente propostos e que foram analisados na íntegra, finalizando com a interpretação e redação do texto.

\section{Resultados e Discussão}

\subsection{Panorama da Qualidade dos Corpos d'água Mato-Grossenses}

O estado do Mato Grosso vem passando por uma ampla expansão da atividade agrícola de monoculturas, pois segundo SIDRA (2019), só o setor de produção agrícola nos municípios, de lavouras temporárias e permanentes, cresceu aproximadamente $350 \%$, saindo de 4.445.242 hectares plantadas em 1999 para 15.619.823 hectares plantadas em 2017. O IBGE (2019a) constatou ainda que em 6 anos (2010 à 2016) o Produto Interno Bruto - PIB do estado cresceu 118\%, ganhando destaque a produção do setor agroindustrial, que aumentou significativamente, contribuindo com 35,04\% do PIB registrado para o ano de 2016, o que comprova a importância desse setor no cumprimento do seu papel social de produzir alimentos para suprir as necessidades internas e externas.

Em contrapartida, associado a esse crescimento, tem-se a utilização intensiva de agrotóxicos e fertilizantes (Soares \& Porto, 2007), evidenciada pelo IBGE (2019b), que afirma que dos 118.676 estabelecimentos agropecuários existentes no estado, cerca de $41 \%$ fizeram utilização desses insumos no ano de 2017. De acordo com IBAMA (2019), nesse mesmo ano, Mato Grosso comercializou 100.638,47 toneladas de ingredientes ativos, tendo a maior participação do país em vendas, representada por 18,64\%. A Figura 1 elaborada por Bombardi (2017) ilustra a porcentagem dos estabelecimentos que utilizaram agrotóxicos em relação ao total de estabelecimentos do município, sendo destacados os cinco primeiros que apresentaram os maiores resultados.

Figura 1 - Uso de Agrotóxicos no Mato Grosso.

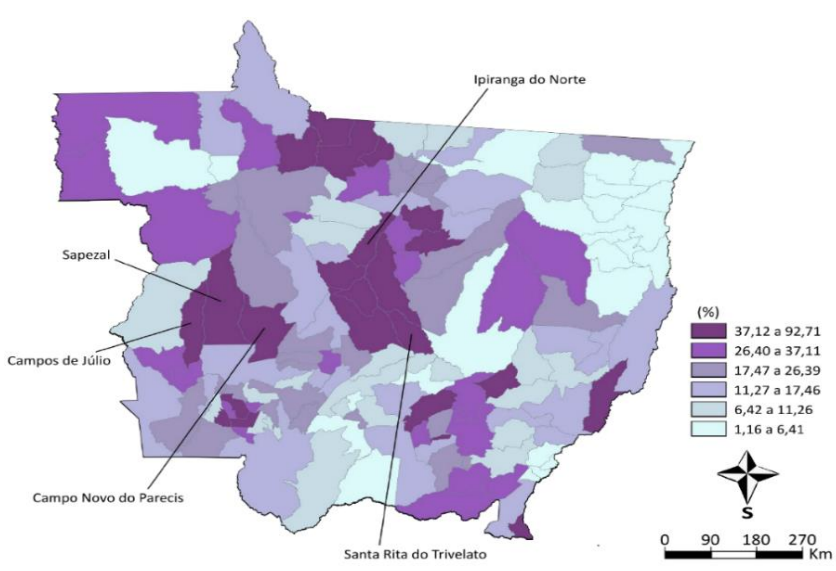

Fonte: Bombardi (2017). 
Entende-se que por si só, a aplicação de agrotóxicos não resolverá o problema de produtividade nas lavouras e nem garantirá suprimento alimentar, mas obrigatoriamente está presente em qualquer programa de melhoramento exequível, juntamente com técnicas agrícolas mais sofisticadas e uso de transgênicos (Soares, 2011). Esse modelo agrário vem acompanhado de crédito rural e subsídios públicos que tornam essas práticas agrícolas mais lucrativas em menor prazo, e como consequência acabam por induzir os fazendeiros a desconsiderarem a deterioração dos recursos naturais (Garcia, 2001).

Van Der Werf (1996) afirma que mesmo havendo uma evolução com relação a constatação dos efeitos da aplicação dos agrotóxicos, sendo instituídas regulamentações expressas no sentido de aumentar as restrições, ocasionando em alguns casos até o banimento, os produtos disponíveis para uso dos agricultores acabam diferindo em relação aos riscos que apresentam para o ambiente. O autor cita ainda que o impacto ambiental provocado, depende do grau de exposição, em razão da dispersão e potencial concentração geradas, bem como das propriedades toxicológicas desses ativos, além disso, adjuvantes agrícolas utilizados para preparar sua aplicação, podem afetar esse processo, estendendo ou retardando a atividade funcional do ingrediente ativo, podendo então ser degradados ou dispersos no ambiente.

Vieira et al. (2011) citam que em caso de aplicação constante dos agrotóxicos, em muitos episódios a praga acaba adquirindo resistência aos diferentes tipos de princípios ativos, de forma que para contornar o problema, são feitas aplicações em doses mais elevadas e com maior frequência. Além disso, as formas de aplicação desses produtos podem contribuir significativamente para os potenciais impactos ambientais causados.

Ramos et al. (2010) sustentam que sem os devidos cuidados, pode-se ocasionar deriva (deslocamento da calda de produtos fitossanitários para fora do alvo desejado), fenômeno que se dá pela ação do vento ou mesmo evaporação (exoderiva) e escorrimentos que atingem o solo (endoderiva), tendendo a se deslocarem principalmente para os corpos d'água superficiais e subterrâneos, sendo estes portanto, o foco dos principais estudos e análises que estão sendo feitos para controle ambiental, por se tratarem em muitos casos de mananciais utilizados no provimento de água potável à população.

Neste cenário, a região mato-grossense possui 3,4 milhões de habitantes distribuídos em 141 municípios (IBGE, 2018a), com grande parte do seu território inserido na Região Hidrográfica Amazônica, sendo que as porções leste e sul do estado encontram-se nas Regiões Hidrográficas do Tocantins-Araguaia e do Paraguai. Do total de municípios, $41 \%$ dependem dos mananciais subterrâneos, $43 \%$ das águas superficiais e 16\% dos dois tipos de mananciais, para o abastecimento da população urbana (ANA, 2018).

O controle de qualidade da água destinada ao consumo humano deve ser realizado conforme os procedimentos determinados pelo Anexo XX da Portaria de Consolidação nº 05 de 28 de setembro de 2017 do Ministério da Saúde - MS, nos quais se inserem os Valores Máximos Permitidos - VMPs de concentração de resíduos de agrotóxicos que foram estabelecidos pela metodologia da Avaliação Quantitativa de Risco Químico - AQRQ (identificação do perigo, avaliação da dose-resposta, avaliação da exposição e caracterização do risco) (Brasil, 2017), além disso, a classificação e diretrizes ambientais para análise da qualidade dos corpos de água (superficiais e subterrâneos), bem como para regulamentação das condições e padrões de lançamento de efluentes nestes, são estabelecidos pelas Resoluções do Conselho Nacional do Meio Ambiente $\mathrm{n}^{\mathbf{o}} 357$ (CONAMA, 2005) e no 396 (CONAMA, 2008), assim como pela NBR 9897 da Associação Brasileira de Normas Técnicas ABNT (1966).

Essas normas baseiam os estudos e análises, por apresentarem um conjunto de variáveis de concentração e caracterização física, química e microbiológica e seus correspondentes limites, proporcionando assim, a avaliação da qualidade da água para os diversos fins de uso. Nesse contexto, no estado mato-grossense alguns autores tratam do monitoramento e a avaliação dos impactos causados nos corpos d'água, pelo uso de agrotóxicos por considerarem essencial para garantir a sustentabilidade no setor agrícola. 
A Tabela 1 compara os valores mínimos e máximos das concentrações dos principais resíduos de agrotóxicos encontrados pelos autores citados abaixo, com o limite máximo legal estabelecido pela Portaria de Consolidação ${ }^{\circ} 05$ de 28 de setembro de 2017 do MS.

Tabela 1. Concentrações de resíduos de agrotóxicos encontradas em Mato Grosso e limite legal.

\begin{tabular}{|c|c|c|c|c|c|c|}
\hline \multicolumn{2}{|c|}{ Agrotóxicos } & Municípios & 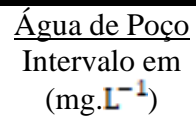 & $\begin{array}{c}\frac{\text { Água superficial }}{\text { Intervalo em }} \\
\left(\mathrm{mg} \cdot \mathrm{L}^{-1}\right)\end{array}$ & $\begin{array}{c}\frac{\text { Água de chuva }}{\text { Intervalo em }} \\
\left(\mathrm{mg} \cdot \mathrm{L}^{-1}\right)\end{array}$ & $\frac{\text { Limite legal }}{\text { VMP }}$ \\
\hline \multirow{3}{*}{ Herbicida } & Atrazina & $\begin{array}{l}\text { Lucas do Rio Verde; Campo } \\
\text { Verde; Campo Novo dos } \\
\text { Parecis; Sapezal; Campos de } \\
\text { Júlio }\end{array}$ & $0,02-18,96$ & $0,01-9,33$ & $0,01-75,43$ & 2 \\
\hline & Deetilatrazina & $\begin{array}{c}\text { Lucas do Rio Verde; Campo } \\
\text { Verde } \\
\end{array}$ & ND & 0,02 & $0,01-13,84$ & $\mathrm{NC}$ \\
\hline & Metolacloro & $\begin{array}{c}\text { Lucas do Rio Verde; Campo } \\
\text { Verde; Campo Novo dos Parecis }\end{array}$ & $0,01-0,24$ & $0,01-0,59$ & $0,01-2,43$ & 10 \\
\hline \multirow{7}{*}{ Inseticida } & Cipermetrina & Lucas do Rio Verde & & & $0,02-0,52$ & $\mathrm{NC}$ \\
\hline & Cloropirifós & Lucas do Rio Verde & $0,02-0,12$ & $0,01-0,04$ & $0,01-0,88$ & 30 \\
\hline & Endosulfan $\alpha$ & $\begin{array}{l}\text { Lucas do Rio Verde; Campo } \\
\text { Verde }\end{array}$ & $0,45-0,82$ & $0,01-0,82$ & $0,01-11,45$ & 20 \\
\hline & Endosulfan $\beta$ & $\begin{array}{l}\text { Lucas do Rio Verde; Campo } \\
\text { Verde }\end{array}$ & $0,01-0,54$ & $0,02-0,94$ & $0,01-1,51$ & 20 \\
\hline & Endosulfan sulfato & $\begin{array}{l}\text { Lucas do Rio Verde; Campo } \\
\text { Verde }\end{array}$ & $0,01-0,10$ & ND & $0,01-7,59$ & 10 \\
\hline & Malationa & $\begin{array}{l}\text { Lucas do Rio Verde; Campo } \\
\text { Verde }\end{array}$ & $0,02-8,83$ & ND & $0,01-7,08$ & $\mathrm{NC}$ \\
\hline & Permetrina & $\begin{array}{c}\text { Lucas do Rio Verde; TI } \\
\text { Marãiwatsédé } \\
\end{array}$ & 1,40 & 0,19 & 0,13 & 20 \\
\hline Fungicida & Flutriafol & $\begin{array}{l}\text { Lucas do Rio Verde; Campo } \\
\text { Verde }\end{array}$ & $0,01-57,11$ & $0,03-0,34$ & $0,02-29,64$ & $\mathrm{NC}$ \\
\hline
\end{tabular}

Nota: VMP = valores máximos permitidos; ND = Não Detectado; NC = Nada Consta.

Fonte: Moreira et al. (2012); Casara (2011); Beserra (2017); Oliveira (2016); Lima (2003); Brasil (2017).

Moreira et al. (2012) analisaram a contaminação de águas superficiais, subterrâneas e de chuva nos municípios de Lucas do Rio Verde e Campo Verde (situam-se entre os maiores produtores de milho, soja e algodão do estado), no período de 2007 à 2009. Os autores levantaram os principais agrotóxicos utilizados nas lavouras, assim como as classificações toxicológicas e de risco ambiental e através de Cromatografia a Gás acoplada com Espectrômetro de Massas - CG/EM, após extração em fase sólida C-18, determinaram quais eram as concentrações de resíduos desses princípios ativos, nas amostras de água coletadas em poços artesianos localizados em propriedades próximas às áreas de plantio e no centro urbano; dois córregos e dois rios das áreas rurais, de cada um dos dois municípios.

Ainda em Campo Verde, Casara (2011) realizou uma análise dos dados de aplicação de pesticidas na região da cabeceira de drenagem do Rio São Lourenço, de 2008 à 2010, a fim de conhecer os produtos que podem oferecer risco ou apresentar potencial de contaminação das suas águas superficiais e subterrâneas. Dessa maneira, através da coleta de amostras de água no local e análise das concentrações de diversos princípios ativos que os compõe (CG/EM e Cromatografia Líquida de Alta Eficiência com detector de diodos - CLAE/DAD), pôde-se constatar a presença de 13 dos 28 pesticidas avaliados, o autor observou ainda que as maiores concentrações foram durante o período de aplicação desses produtos.

Nos municípios de Campo Novo do Parecis, Sapezal e Campos de Júlio, Beserra (2017) realizou a mesma análise em amostras de água coletadas em poços artesianos e da chuva em escolas rurais e urbanas dessas regiões, sendo detectada a presença de princípios ativos em 66\% das amostras coletadas nos poços e 86\% das coletadas da chuva. Oliveira (2016) também analisou esses municípios (situados na bacia do rio Juruena), sendo que das 18 amostras de água coletadas no estudo, em 7 foram detectados resíduos de agrotóxicos. Essa presença é explicada por Oliveira et al. (2018), que afirmam existir poluição química na região devido ao elevado uso de agrotóxicos por habitante - 350 a 600 1/hab./ano. 
Lima (2003), avaliou a contaminação hídrica por agrotóxicos na Terra Indígena Marãiwatsédé localizada em uma região que engloba os municípios de Alto Boa Vista, Bom Jesus do Araguaia e São Félix do Araguaia (considerada a terra indígena mais desmatada da Amazônia Legal), e através do método CG/EM, constatou que dos 7 locais amostrados apenas 1 apresentou resultado positivo para resíduo de agrotóxicos na água.

Silva \& Queiroz (2016) realizaram análises de ocorrência de um fungicida (Protioconazol) e um herbicida (2,4-D), através da CLAE, nas águas dos principais mananciais superficiais disponíveis no Assentamento Antônio Conselheiro (AAC), pertencente ao município de Tangará da Serra, não sendo detectada a presença desses em limites superiores a 0,001 mg. $\mathrm{L}^{-1}$, sendo que esse valor era o limite de detecção - LD do aparelho. Nesse caso, se há contaminação é provável que a concentração esteja abaixo do LD.

A Secretaria de Vigilância em Saúde (2014) divulgou um diagnóstico do monitoramento de agrotóxicos na água para consumo humano no Brasil, realizado a partir de análises de dados do Sistema de Informação de Vigilância da Qualidade da Água para Consumo Humano - Sisagua. Dos 1.598 municípios monitorados, 21\% apresentaram algum resultado acima do VMP, sendo que no Mato Grosso, os municípios de Alto Garças, Cláudia, Juara, Lucas do Rio Verde, Nova Canaã do Norte, Peixoto de Azevedo, Pontal do Araguaia, Porto Esperidião, Sapezal e Terra Nova do Norte, estão entre eles. Dentre os princípios ativos acima do VMP destacam-se Aldrim/Drieldrim, Clordano, Endrin, Atrazina e DDT que totalizam 93,8\% das substâncias quantificadas no país.

Percebe-se que as análises com coleta de água superficial foram prevalentes para os estudos revisados, tendo para alguns o acréscimo de água subterrânea e de chuva. Não houve relação entre os estudos, referente a quantidade de pontos amostrados e período de coleta, possuindo diferentes determinações de locais de coleta (rural e urbano) e valores variando de 6 (Beserra, 2017; Silva \& Queiroz, 2016) à 44 (Moreira \& Belo, et al., 2012).

Dos princípios ativos avaliados, os constantes na Tabela 1 foram os mais frequentes, obtendo em sua maioria concentrações inferiores a legislação brasileira, com exceção do herbicida Atrazina, que no estudo de Moreira et al. (2012a) alcançou o valor de 75,43 mg.L $\mathrm{L}^{-1}$ em amostra de água da chuva e mesmo em águas superficiais e subterrâneas, esteve presente em todas as regiões (exceto a TI Marãiwatsédé) com as maiores concentrações quando comparados aos outros agrotóxicos.

Observa-se também uma alta concentração do inseticida Endolsufan, porém, vale ressaltar que, este foi proibido no país a partir de 2013, posterior as pesquisas, bem como, que a escolha dos princípios ativos em todos os estudos, foi em função da sua quantificação de utilização em lavouras das regiões, assim a probabilidade de serem encontrados em maior quantidade aumenta, pois segundo Pignati et al. (2014), todos os princípios ativos constantes na tabela 1, estão entre os 31 mais utilizados no estado.

Além disso, as concentrações em água da chuva se mostraram superiores as das águas superficiais e subterrâneas, bem como as maiores ocorrências foram em períodos de aplicação, evidenciando assim, uma relação com o processo de exoderiva. Com relação aos princípios ativos Deetilatrazina (produto da degradação da Atrazina), Cipermetrina, Malationa e Flutriafol, que se fizeram presentes nos corpos d'água das regiões estudadas, não existem limites de concentração legislados no país, tornando assim, esses mananciais impróprios para consumo humano, até que se avalie o risco da presença dessas substâncias.

Ademais, ressalta-se a existência de legislações internacionais, sendo a da União Européia - UE (1998) a mais restritiva, que considera o valor limite de resíduos em água potável de $0,1 \mathrm{mg} . \mathrm{L}^{-1}$ por ingrediente de agrotóxico e seus metabólitos (que não sejam o Aldrin, o Dieldrin, o Heptacloro e o Heptacloro Epóxido, valor limite de 0,030 mg.L-1 ), sendo que para o somatório de todas as ocorrências de resíduos, o valor é de 0,5 mg. $\mathrm{L}^{-1}$. Deste modo, grande parte dos princípios ativos analisados, comprometem a potabilidade da água de acordo com esse parâmetro, porém os limites estabelecidos pela UE não consideram a toxicidade das substâncias e, portanto, não podem ser usados para avaliação de risco. 


\subsection{Avaliação dos Impactos Potenciais da Contaminação da Água para Consumo Humano}

O Brasil têm, segundo Bombardi (2017), 504 agrotóxicos de uso autorizado, destes $30 \%$ já são proibidos na União Europeia há mais de uma década, porém, aqui no país estão no ranking dos mais comercializados, sendo que apenas $6 \%$ do total são regulamentados sobre os VMPs da concentração dos seus resíduos em águas para consumo (Brasil, 2011; CONAMA, 2008; CONAMA, 2005).

Os agrotóxicos possuem composição química variada, tendo classificações específicas de acordo com: sua ação na espécie alvo, avaliada pelo Ministério da Agricultura Pecuária e Abastecimento - MAPA; sua toxicidade para o ambiente, medida pelo Ministério do Meio Ambiente - MMA, por meio do Instituto Brasileiro do Meio Ambiente e dos Recursos Naturais Renováveis - IBAMA e; sua toxicidade para os seres humanos, determinada pelo Ministério da Saúde - MS por meio da Agência Nacional de Vigilância Sanitária - ANVISA.

Segundo Lima (2003), para determinar a classe de toxicidade que indica o grau de perigo dos agrotóxicos à saúde humana, são realizadas análises laboratoriais que estabelecem uma Dose Letal - DL50, que representa a concentração da substância que é capaz de matar metade (50\%) da população (geralmente ratos) utilizada na análise, medida em miligramas de substância por quilograma de massa corporal dos indivíduos testados (extrapolada para humanos), conforme Tabela 2.

Além disso, esta classificação deve ser exibida no rótulo da embalagem do princípio ativo, assim como a sua classificação ambiental (Potencial de Risco ao Meio Ambiente - PPA), que baseia-se nos parâmetros de bioacumulação, persistência, transporte, toxicidade a diversos organismos, potencial mutagênico, teratogênico e carcinogênico, e obedece a seguinte graduação: Classe I - Altamente Perigosos; Classe II - Muito Perigosos; Classe III - Perigosos; Classe IV - Pouco Perigosos, recebendo ainda um código de cores.

Tabela 2. Classe toxicológica de agrotóxicos segundo a dose letal DL50 e cor do rotulo da embalagem.

\begin{tabular}{ccccc}
\hline Classe toxicológica & Toxicidade & DL50 oral (mg/kg) & Dose capaz de matar uma pessoa adulta & $\begin{array}{c}\text { Faixa } \\
\text { colorida }\end{array}$ \\
\hline I & Extremamente tóxico & $\leq 5$ & 1 pitada - algumas gotas & Vermelho \\
II & Altamente tóxico & $5<$ DL50 $\leq 50$ & 1 colher de chá & Amarelo \\
III & Moderadamente tóxico & $50<$ DL50 $\leq 500$ & 1 colher de chá -2 colheres de sopa & Azul \\
IV & Pouco tóxico & DL50 $>5000$ & 1 copo - litro & Verde \\
\hline
\end{tabular}

Fonte: Ministério da Saúde (1992) e Trapé (1993).

Vale ressaltar que de acordo com a classificação todos os agrotóxicos são nocivos à saúde humana e ao meio ambiente, pois mesmo mediante pouca exposição e/ou baixas doses, se este for faixa vermelha, por exemplo, pode ser letal. Além disso, essa classificação refere-se apenas a toxicidade da formulação, ou seja, serve como importante indicativo do potencial de desencadear algum agravo agudo, não sendo, portanto, parâmetro para longas exposições que possam causar algum agravo crônico (Beserra, 2017).

A Tabela 3 demonstra as classificações relacionadas ao alvo espécie, grupo químico, toxicidade humana, PPA e modo de ação dos principais ingredientes ativos encontrados nos estudos de análises de água no estado mato-grossense, com o intuito de compreender o processo de contaminação desses mananciais. Cada grupo químico apresenta um radical comum que confere a todos os compostos derivados sua capacidade de ação na espécie alvo. Conforme apresentado, o modo de ação pode ser sistêmico ou de contato, sendo que o primeiro age circulando através da seiva por todos os tecidos vegetais, de forma a se distribuir uniformemente e ampliar o seu tempo de ação, já o segundo, tem ação externa no vegetal, (embora uma quantidade pequena possa ser absorvida) atingindo diretamente o alvo biológico (Silva \& Fay, 2004). 
Tabela 3. Classificação dos principais agrotóxicos utilizados em Mato Grosso.

\begin{tabular}{|c|c|c|c|c|c|}
\hline Ingrediente Ativo & Espécie alvo & Grupo Químico & Modo de ação & $\begin{array}{c}\text { Classe Toxicidade } \\
\text { Humana - } \\
\text { ANVISA }\end{array}$ & $\begin{array}{c}\text { Classe Toxicidade Ambiental } \\
\text { (PPA) - IBAMA }\end{array}$ \\
\hline $\begin{array}{c}\text { Atrazina } \\
\text { Desetilatrazina }\end{array}$ & \multirow[t]{2}{*}{ Herbicida } & Triazina & Sistêmico & III & III \\
\hline Metolacloro & & Cloroacetanilida & Sistêmico & III & II \\
\hline Cipermetrina & \multirow{5}{*}{ Inseticida } & Piretróide & Contato & II & II \\
\hline Clorpirifós & & Organofosforado & Contato & II & I \\
\hline Endosulfan & & ciclodienoclorado & Contato & I & I \\
\hline Malationa & & Organofosforado & Contato & III & III \\
\hline Permetrina & & Piretróide & Contato & III & II \\
\hline Flutriafol & Fungicida & Triazol & Sistêmico & III & III \\
\hline
\end{tabular}

Fonte: ANVISA (2019) e Pignati et al. (2014).

Após o contato com o ambiente de aplicação, esses agrotóxicos passam por vários processos físicos, químicos e biológicos que determinam seu destino e que por vezes, seus resíduos podem ser mais tóxicos do que os componentes originais, sendo que o conhecimento dessa dinâmica ambiental é essencial para determinar medidas mitigadoras de contaminação, principalmente em ecossistemas vulneráveis, como o dos recursos hídricos (Casara, 2011).

Oliveira (2016) aborda que as propriedades físico-químicas dos agrotóxicos também são aspectos muito importantes para estimar o comportamento destes no ambiente, sendo as principais delas, densidade (relação entre a sua massa por unidade de volume), solubilidade (capacidade de se dissolver em água pura), ionizabilidade (refere-se à força de ionização), pressão de vapor (pressão à determinada temperatura em que a fase de gás está em equilíbrio com a fase líquida) e meia-vida (tempo para que metade da concentração de agrotóxico desapareça). Além disso, condições meteorológicas (direção e velocidade do vento, temperatura, umidade relativa, estabilidade atmosférica, etc.) e manejo, também influenciam.

Nesse sentido, conforme os estudos no estado, a aplicação intensa da Atrazina, que possui baixa reatividade, mobilidade, persistência e solubilidade, favorecendo seu transporte via escoamento superficial, lixiviação e deposição atmosférica, acaba impactando o meio ambiente, pois seus resíduos e metabólitos permanecem após longo período da aplicação, possuindo tempo de vida médio de 20 à mais de 100 dias (Santos, 2010).

Já o Metolacloro possui alta persistência, sendo que suas características físico-químicas, como pressão de vapor relativamente elevada, explicam sua presença na atmosfera e por consequência na água da chuva, além disso, sua volatilidade e alta solubilidade colabora para que seu tempo de meia-vida na água seja de 365 dias (Beserra, 2017).

O Endossulfan é estável à ação da luz solar, pouco estável na presença de ácidos e insolúvel em água, porém é solúvel na maioria dos solventes orgânicos, dessa forma, tem efeito bioacumulativo ao longo da cadeia alimentar, por possuírem baixa biodegradabilidade, podendo persistir por 15 a 20 anos no solo e parte destes serem arrastados pelas chuvas, por lixiviação, para o interior dos cursos de água (Rissato et al., 2004). Em consequência disso, a ANVISA deliberou no ano de 2009 o banimento desse inseticida, classificado com extremamente tóxico (classe I), sendo sua importação proibida em julho de 2011 e sua comercialização e uso proibidos em julho de 2013.

O Flutriafol é lixiviável, estável e tem elevada meia-vida no solo, por possuir moderada mobilidade e embora seu destino e comportamento na água seja pouco conhecido, as altas taxas de pulverização indicam uma provável contaminação de água superficial e subterrânea, pois estudos constataram sua persistência e acumulação no solo e na água (Santos, 2010). Assim sendo, na água um agente químico pode apresentar-se de três formas diferentes: dissolvido; adsorvido pelos componentes bióticos e abióticos, suspenso na coluna d'água ou depositado no sedimento e; incorporado nos organismos (Brondi, 2000).

Por conseguinte, a contaminação dos mananciais de água, que em muitos casos são utilizados para consumo humano, além de comprometer a biodiversidade existente nestes, pode acarretar ainda a intoxicação da população, seja por 
contato/exposição com a água contaminada ou ingestão dela, não refletindo uma simples relação entre produto e indivíduo exposto, mas sim, uma diversidade de fatores que acarretaram as condições de exposição.

Nesse sentido, a Organização Pan-Americana de Saúde/Organização Mundial de Saúde - OPAS/OMS (1997) afirmam que as características clínicas das intoxicações por agrotóxicos dependem se o contato/exposição foi a um único tipo de produto ou a vários deles. Nas intoxicações agudas decorrentes de apenas um produto, os sinais e sintomas clínicolaboratoriais são bem conhecidos, o diagnóstico é claro e o tratamento definido, já em relação às intoxicações crônicas, o quadro clínico é indefinido e o diagnóstico difícil de ser estabelecido, conforme sintomas descritos na Tabela 4. Essa afirmação evidencia a necessidade de estudos voltados para a avaliação de exposições crônicas causadas por fatores como bioacumulação e biomagnificação.

Tabela 4. Sinais a sintomas de intoxicação por agrotóxico segundo tipo de exposição.

\begin{tabular}{|c|c|c|}
\hline \multirow{2}{*}{ Sinais e sintomas } & \multicolumn{2}{|c|}{ Exposição } \\
\hline & Única ou por curto período & Continuada por longo período \\
\hline Agudos & $\begin{array}{c}\text { Cefaléia } \\
\text { Tontura } \\
\text { Náusea } \\
\text { Vômito } \\
\text { Fasciculação muscular } \\
\text { Parestesias Desorientação } \\
\text { Dificuldade respiratória } \\
\text { Coma } \\
\text { Morte } \\
\end{array}$ & $\begin{array}{l}\text { Hemorragias } \\
\text { Hipersensibilidade } \\
\text { Terafogénese } \\
\text { Morte fetal }\end{array}$ \\
\hline Crônicos & $\begin{array}{c}\text { Paresia e paralisia reversíveis } \\
\text { Ação neurotóxica retardada irreversível } \\
\text { Pancitopenia } \\
\text { Distúrbios neuropsicológicos }\end{array}$ & $\begin{array}{c}\text { Lesão cerebral irreversível } \\
\text { Tumores malignos } \\
\text { Atrofia testicular } \\
\text { Esterilidade masculina } \\
\text { Alterações neurocomporta mentais } \\
\text { Neurifes periféricas } \\
\text { Dermatites de contato } \\
\text { Formação de catarata } \\
\text { Atrofia do nervo óptico } \\
\text { Lesbes hepáticas,etc. } \\
\end{array}$ \\
\hline
\end{tabular}

Fonte: OPAS e OMS (1997)

Dentre os principais distúrbios do sistema nervoso apresentados, vários foram associados à exposição aos agrotóxicos organofosforados, principalmente aqueles ligados à efeitos neurológicos retardados, sendo que esses inseticidas têm como uma de suas principais características a capacidade de acumular-se nas células gordurosas do organismo humano, podendo ocasionar uma série de efeitos indesejados à saúde (Peres \& Moreira, 2003).

Peres e Moreira (2003) ressaltam que as alergias, que acabam por desencadear episódios de asma e bronquite, principalmente em crianças, são geralmente atribuídas aos agrotóxicos piretróides, estes por sua vez, por ser o grupo mais recente de inseticidas no mercado, são menos tóxicos aos mamíferos do que os demais.

Mediante o exposto, a ANVISA (2019b) estabelecerá pela primeira vez no país, uma pontuação de risco que guiará as próximas reavaliações de agrotóxicos, feita através de parâmetros próprios do grau de toxicidade com potencial risco a saúde humana, baseados em informações científicas e dados atualizados, inclusive de referências internacionais de entidades como a Autoridade Européia para Segurança Alimentar (European Food Safety Authority - EFSA) e a Agência de Proteção Ambiental dos Estados Unidos (United States Environmental Protection Agency - USEPA), que de acordo com a Gerência Geral de Toxicologia - GGTOX, facilitará a escolha dos ingredientes ativos a serem reconsiderados.

\subsection{Metodologias para Deteç̧ão de Agrotóxicos na Água}

Segundo Neto e Sarcinelli (2004) a presença de resíduos de agrotóxicos nos mananciais pode trazer dificuldades para o tratamento de água para consumo humano, visto a necessidade de aplicação de tecnologias mais complexas do que as 
utilizadas normalmente para potabilização. Além disso, Brondi (2007) ressalta ainda que os baixos níveis de concentração, a diversificação e as diferentes propriedades físico-químicas destes, associados às altas concentrações de compostos interferentes complicam as análises.

A análise de agrotóxicos na água envolve as etapas de amostragem, pré-tratamento das amostras, medida (detecção) e tratamento dos dados. De modo que os estágios iniciais da análise é primordial na avaliação de riscos, sendo necessária a observação de interferências que poderão afetar a identificação e a quantificação dos resíduos de agrotóxicos, aplicando-se para tanto métodos de isolamento e préconcentração do analito de interesse, existindo assim, diferentes técnicas de concentração ou remoção da matriz (Bruzzoniti et al., 2000).

A Extração Líquido - Líquido (LLE) é o procedimento de separação mais simples, que consiste em separar os componentes dos solutos por partição entre dois sistemas imiscíveis, fazendo com que as substâncias presentes se distribuam entre os dois solventes de acordo com a solubilidade relativa a cada uma, que depende da sua composição física e química, de forma rápida e conveniente (Brondi, 2000). Para este método parte-se do princípio que os compostos são solúveis em solventes orgânicos e muito pouco solúveis em água.

Outra técnica de separação usual, nesse caso empregada tanto para análise de analitos polares como para não polares, onde a amostra e o analito devem estar dissolvidos em um líquido é a Extração em Fase Sólida - SPE, que consiste no preparo de amostras, onde pequenas colunas descartáveis são preenchidas com uma grande variedade de adsorventes, podendo ser adicionadas a elas grandes volumes de amostras, portanto, conveniente nas análises com água, proporcionando a obtenção de concentrações de analito suficientes para detecção de forma eficiente, rápida, segura e seletiva (Brondi, 2000).

As técnicas cromatográficas são usuais, por conta da sua capacidade de identificação e quantificação desses compostos, sendo que a Cromatografia Gasosa-CG acoplada a sistemas clássicos de detecção como, Detecção por Captura de Elétrons-DCE, Detecção de Nitrogênio e Fósforo-DNF e Detecção por Fotometria de Chama-DFC, tem sido empregada para análise de resíduos de agrotóxicos desde 1970, porém, com a evolução temporal desses princípios ativos que passaram de persistentes e não degradáveis para mais polares e degradáveis, com melhor ação e menor impacto ambiental, torna-se necessário técnicas mais sensíveis e eficazes para análise dos produtos da sua degradação (Fernández-Alba, 2005).

Nesse sentido, Fernández-Alba (2005) afirma que atualmente a Cromatografia Líquida de Alta Eficiência com Detecção por Arranjo de Diodos - CLAE/DAD ou acoplada à Espectrometria de Massas - CL/EM tem obtido maior viabilidade, pois permite atingir a sensibilidade e seletividade propícia para avaliar resíduos de agrotóxicos em matrizes ambientais. Por conta do avanço instrumental que possibilitou um sistema de injeção de grandes volumes (de extrato e por consequência analitos), programação da temperatura de vaporização, houve a facilitação na identificação e quantificação de analitos em níveis inferiores aos estabelecidos pelos VMPs, em função da melhor resposta cromatográfica.

Além destes, outro método usual é a CG acoplada ao EM, devido a facilidade de acoplamento, uma vez que as características de funcionamento do cromatógrafo a gás são suficientemente compatíveis com a necessidade de alto vácuo do espectrômetro de massas, bem como da disponibilidade de um banco de espectros de massas padrão obtidos no modo de ionização por impacto de elétrons e quantificação e determinação de um grande número de compostos simultaneamente (Chiaradia et al., 2008). Porém, de acordo com Peters e Remane (2012), a CG/EM não possui eficiência na análise de amostras não voláteis, hidrofílicas e termolábeis, sendo a CL/EM capaz de cobrir essa lacuna.

Por conseguinte, Floss (2015) afirma que os laboratórios necessitam utilizar ferramentas de validação regulamentadas pelos órgãos competentes, sendo que a ANVISA, Instituto Nacional de Metrologia, Normalização e Qualidade Industrial INMETRO entre outros, estabelecem as diretrizes necessárias no Brasil, já para os órgãos internacionais tem-se, por exemplo, a União Internacional de Química Pura e Aplicada - IUPAC, Organização Internacional para Padronização - ISO e 
Conferência Internacional em Harmonização - ICH. Geralmente são avaliadas a seletividade e sensibilidade, linearidade e curva analítica, exatidão e precisão, limite de detecção (LOD) e limite de quantificação (LOQ).

Em função do crescimento da demanda e dos custos elevados desses métodos analíticos usuais, estudos estão sendo desenvolvidos para avaliar técnicas de tratamento adequadas e mais econômicas, como o filtro-boia, GlyFloat, desenvolvido pela Equipe de Biologia Sintética da UFRGS (UFRGS CIÊNCIA, 2019) onde microrganismos são programados biologicamente para degradar resíduos de glifosato na água, bem como da espuma de poliuretano, desenvolvida por pesquisadores da Universidade Federal de Minas Gerais - UFMG (Revista Pazes, 2019), capaz de detectar e absorver herbicidas da água.

Nesse contexto, observa-se que nos trabalhos avaliados no presente estudo, majoritariamente foi realizada a extração por fase sólida dos princípios ativos, de modo que a identificação e determinação das concentrações destes foram feitas por CG.

\subsection{Políticas Públicas Voltadas para o Tratamento Adequado da Água Contaminada por Agrotóxicos}

Desde a década de 1990 foi estabelecida no Brasil a portaria n 36 do MS, determinando os procedimentos para o controle e a vigilância da qualidade da água para consumo humano e seu padrão de potabilidade, estabelecendo assim, a obrigatoriedade do monitoramento da contaminação de agrotóxicos nos recursos hídricos para este fim, de forma que ao longo dos anos novas portarias (Portaria MS nº 1469/2000, Portaria MS nº 518/2004, Portaria MS nº 2.914/2011, e a atual Portaria de consolidação $n^{\circ}$ 05/2017) foram sendo publicadas no intuito de melhorar esse acompanhamento.

No âmbito do MS, a execução de ações que forneçam o conhecimento e a detecção nos fatores determinantes e condicionantes do meio ambiente que interferem na saúde humana, principalmente referentes aos contaminantes químicos de maior relevância, como os agrotóxicos, competem à Secretaria de Vigilância em Saúde - SVS, que as realizam através do Subsistema Nacional de Vigilância em Saúde Ambiental - SINVSA, e tem portanto a função de desenvolver medidas de prevenção e de controle dos fatores de risco (Brasil, 2017). Nesse sentido ainda, foi criada a Vigilância em Saúde de Populações Expostas a Agrotóxicos - VSPEA, amparada pela publicação da portaria nº 2.938 (MS, 2012).

Dessa forma, os estados e Distrito Federal devem implementar essas diretrizes respeitando os princípios do Sistema Único de Saúde - SUS e prioridades, objetivos, metas e indicadores do Programa Nacional da Vigilância da Qualidade da Água para Consumo Humano - Vigiagua, sendo os municípios responsáveis por definir o plano de amostragem em consonância com a legislação, que estabelece no mínimo uma amostra de água por semestre para análise dos agrotóxicos prioritários (considerando os aspectos socioambientais e as especificidades locais) (Brasil, 2016).

Neto e Sarcinelli (2004) esclarecem que a Organização Mundial de Saúde - OMS indica que, referente às substâncias químicas que representam risco à saúde humana e seus parâmetros com os respectivos VMPs, devem ser priorizadas e incluídas na legislação aquelas mais relevantes segundo cada realidade.

Os autores afirmam ainda que devem ser avaliados os requisitos de: "análise das evidências epidemiológicas e toxicológicas associados às substâncias", levando em consideração bibliografia da OMS, Environmental Protect Agency - EPA e International Agency for Research on Cancer - IARC; "potencial tóxico das substâncias que podem estar presentes na água naturalmente ou por contaminação"; magnitude de uso dos ingredientes ativos no país; possibilidade de obtenção/limitação de padrões e metodologias analíticas utilizadas atualmente e; "comparação dos valores guias da OMS, normas dos EUA, Canadá e Comunidade Europeia e os VMPs definidos na legislação nacional em vigor”.

Peres \& Moreira (2003) citam que referente às limitações dos métodos de análise, os cromatográficos apresentam alto custo em comparação aos métodos de análise tradicionais dos sistemas de abastecimento urbano, por necessitarem de técnicas sofisticadas (incluindo, mão de obra qualificada), manutenção periódica dos equipamentos e a obrigatoriedade de testar um 
grande número de padrões, visto a carência de dados relativos aos produtos efetivamente mais usados. Os autores alegam que em função disso, no Brasil não existe um programa continuado e amplo voltado ao monitoramento de agrotóxicos no ambiente.

Mediante o exposto, considerando a legislação vigente, cabe ao setor de saúde, estimular e fortalecer suas atuações referentes ao monitoramento de agrotóxicos na água para abastecimento urbano, visando à prevenção de agravos e a manutenção da saúde, salienta-se ainda, a necessidade de articulação entre as Secretarias de Saúde dos Estados e do Distrito Federal com os diversos setores incluídos nessa questão, tais como: Secretarias de Agricultura, de Recursos Hídricos, de Meio Ambiente, dentre outros, no intuito de efetivar a implantação do monitoramento dessas substâncias, através de ações e estratégias intra e intersetoriais para a melhoria da situação existente (MS, 2013).

\section{Considerações Finais}

Constatou-se o comprometimento da qualidade dos corpos d'água no estado mato-grossense pela presença de princípios ativos considerados extremamente e altamente tóxicos à saúde humana, bem como altamente e muito perigosos ao meio ambiente. Ressalta-se assim, a importância do plano de monitoramento nesses municípios, visto que ao longo dos anos esse panorama pode ter se intensificado mediante a expansão agrícola e o consequente aumento da quantidade de agrotóxicos utilizadas.

Os impactos sociais referentes a constatação dos sinais e sintomas epidemiológicos e de toxicidade ocasionados pelas exposições agudas ou crônicas foram relatados, e mediante a contaminação existente, se tornam um alerta para a utilização de metodologias de análises adequadas nas estações de tratamento de água para abastecimento urbano.

Assim, verificou-se que apesar de existir legislações vigentes de controle da qualidade da água, há falhas no cumprimento e no monitoramento desses princípios ativos, motivo que é associado ao alto custo das metodologias analíticas, além disso, a maior parte das análises feitas partem de universidades por serem de interesse público e acadêmico, não fazendo parte do enfoque político e econômico, reforçando a necessidade de trabalhos futuros voltados para novos métodos de análise com baixo custo, bem como reavaliações dos agrotóxicos mais rígidas, como na UE.

\section{Referências}

ABNT, A. B. de N. T. (1987). NBR 9897: Planejamento de amostragem de eflentes líquidos e corpos receptores. 14. http://licenciadorambiental.com.br/wpcontent/uploads/2015/01/NBR-9.897-Planejamento-de-amostras.pdf

ANVISA, A. N. de V. S. (2018). Monografias autorizadas - Anvisa. Regularização de Produtos - Agrotóxicos. http://portal.anvisa.gov.br/registros-eautorizacoes/agrotoxicos/produtos/monografia-de-agrotoxicos/autorizadas.

ANVISA, A. N. de V. S. (2019). Pontuação de risco irá guiar reavaliação de agrotóxicos. http://portal.anvisa.gov.br/noticias//asset_publisher/FXrpx9qY7FbU/content/pontuacao-de-risco-ira-guiar-reavaliacao-de-

agrotoxicos/219201?p_p_auth=bIKzFTIk\&inheritRedirect=false\&redirect=http\%25253A\%25252F\%25252Fportal.anvisa.gov.br\%25252Fnoticias\%25253F

Arias, A. R. L., Buss, D. F., Alburquerque, C. de, Inácio, A. F., Freire, M. M., Egler, M., Mugnai, R., \& Baptista, D. F. (2007). Utilização de bioindicadores na avaliação de impacto e no monitoramento da contaminação de rios e córregos por agrotóxicos. Ciência \& Saúde Coletiva, 12(1), 61-72. 10.1590/s141381232007000100011

Beserra, L. (2017). Agrotóxicos, vulnerabilidades socioambientais e saúde: uma avaliação participativa em municípios da bacia do rio Juruena, Mato Grosso [Universidade Federal de Mato Grosso]. http://www1.ufmt.br/ppgsc/arquivos/7482ec1ed28ff2985ffdceea860bf123.pdf?fbclid=IwAR1Az jnal37K0xy2CzPm_oT8snE5TxA4m3IxijKxvmyhb6wI1u9-o56O7Us

Bombardi, L. M. (2017). Geografia do uso de agrotóxicos no brasil e conexões com a União Europeia (1º ed): Universidade de São Paulo.

Brasil, M. da S. (2011). Portaria $n^{o}$ 2.914, de 12 de Dezembro de 2011 . Diário Oficial da União (DOU). http://bvsms.saude.gov.br/bvs/saudelegis/gm/2011/prt2914_12_12_2011.html

Brasil, M. da S. (2017). Portaria de consolidação $n^{\circ} 5$ de 28 de setembro de 2017 . Gabinete do Ministro. http://bvsms.saude.gov.br/bvs/saudelegis/gm/2017/prc0005_03_10_2017.html

Brasil, M. da S. S. de V. em S. D. de V. em S. A. e S. do T. (2017). Diretrizes Nacionais para a Vigilância em Saúde de Populações Expostas a Agrotóxicos. In Ministério da Saúde (Org.), Ministério da Saúde (1º ed). Ministério da Saúde. 10.1155/2014/598129

Brasil, M. da S. S. de V. em S. D. de V. em S. A. e S. do T. (2016). Diretriz Nacional do Plano de Amostragem da Vigilância da Qualidade da Água para 
Consumo Humano [recurso eletrônico] (Ministério da Saúde $\quad$ (org.); $1^{\circ} \quad$ ed). Ministério $\quad$ da $\quad$ Saúde. http://bvsms.saude.gov.br/bvs/publicacoes/diretriz_nacional_agua_consumo_humano.pdf

Brondi, S. H. G. (2000). Determinação de multiresiduos de agrotóxicos em águas de abastecimento do município de Araraquara: Ribeirão das Cruzes, Ribeirão das Anhumas e Córrego do Paiól. In Tese (Doutorado). Universidade de São Paulo.

Bruzzoniti, M. C., Sarzanini, C., \& Mentasti, E. (2000). Preconcentration of contaminants in water analysis. Journal of Chromatography A, 902(1), 289-309. 10.1016/S0021-9673(00)00838-4

Casara, K. P. (2011). Dinâmica ambiental de pesticidas em área de nascente degradada do rio São Lourenço, Mato Grosso. In Dissertação (mestrado). Universidade Federal de Mato Grosso.

Chiaradia, M. C., Collins, C. H., \& Jardim, I. C. S. F. (2008). O estado da arte da cromatografia associada à espectrometria de massas acoplada à espectrometria de massas na análise de compostos tóxicos em alimentos. Quimica Nova, 31(3), 623-636.

CONAMA, C. N. D. M. A. (2005, março). Resolução CONAMA nº 357, de 17 de março de 2005. Diário Oficial da União (DOU), Seção 1, 23.

CONAMA, C. N. D. M. A. (2008, abril). Resolução CONAMA n 396, de 3 de abril de 2008. Diário Oficial da União (DOU), Seção 1, 64-68. https://doi.org/10.1177/1474022208

De Oliveira, L. K., Pignati, W., Pignatti, M. G., Beserra, L., \& Leão, L. H. D. C. (2018). Socio-sanitary-environmental process of pesticides in the basin of the rivers Juruena, Tapajós and Amazonas in Mato Grosso, Brazil. Saúde e Sociedade, 27(2), 573-587. 10.1590/s0104-12902018170904

Fernández-Alba, A. R. (2005). Chromatographic-mass spectrometric food analysis for trace determination of pesticide residues (E. Science (org.)). Elsevier. https://books.google.com.br/books/about/Chromatographic_Mass_Spectrometric_Food.html?id=shpI6d9BFwkC\&printsec=frontcover\&source=kp_read_butto n\&redir_esc $=\mathrm{y} \# \mathrm{v}=$ onepage $\& \mathrm{q} \& \mathrm{f}=$ false

Floss, V. M. (2015). Determinação multirresíduo de agrotóxicos em água empregando Microextração Líquido-Líquido Dispersiva (DLLME) e GC-MS/MS. In Dissertação de mestrado centro de ciências naturais e exatas programa de pós-graduação em química determinação. Universidade Federal de Santa Maria.

Garcia, E. G. (2001). Segurança e saúde no trabalho rural: a questão dos agrotóxicos. In Mte/Fundacentro. Universidade de São Paulo.

Gomes, M. A. F., \& Barizon, R. R. M. (2014). Panorama da Contaminação Ambiental por Agrotóxicos e Nitrato de origem Agrícola no Brasil: Cenário 1992/2011. Embrapa Meio Ambiente, 35.

IBAMA, (2019). Relatórios de comercialização de agrotóxicos. https://www.ibama.gov.br/agrotoxicos/relatorios-de-comercializacao-deagrotoxicos\#historicodecomercializacao

IBGE,. (2018). IBGE prevê safra de grãos 1,7\% maior em 2019. Editoria: Estatísticas Econômicas. https://agenciadenoticias.ibge.gov.br/agencia-sala-deimprensa/2013-agencia-de-noticias/releases/23359-ibge-preve-safra-de-graos-1-7-maior-em-2019

IBGE, (2019a). IBGE | Brasil em Síntese | Mato Grosso | Pesquisa | Censo Agropecuário - Características dos estabelecimentos. https://cidades.ibge.gov.br/brasil/mt/pesquisa/24/76693

IBGE, (2019b). IBGE | Brasil em Síntese | Mato Grosso | Pesquisa | Contas Regionais do Brasil | PIB a preços correntes | 2016. https://cidades.ibge.gov.br/brasil/mt/pesquisa/10060/60147?indicador=60152\&ano=2016

Lima, F. A. N. D. S. E. (2003). Saúde, ambiente e contaminação hídrica por agrotóxicos na Terra Indígena Marãiwatsédé, Mato Grosso. Francco. In Dissertação (mestrado). Universidade Federal de Mato Grosso.

Moreira, J. C., Belo, M. S. da S. P., Pignati, W., Peres, F., \& Dores, E. F. G. de C. (2012). Uso de agrotóxicos na produção de soja do estado do Mato Grosso: um estudo preliminar de riscos ocupacionais e ambientais. Revista Brasileira de Saúde Ocupacional, 37(125), 78-88. 10.1590/s0303-76572012000100011

Moreira, J. C., Peres, F., Simoes, A. C., Pignati, W. A., Dores, E. C. de C., Vieira, S. N., Strussmann, C., Mott, T., Simões, A. C., Pignati, W. A., Dores, E. C. de C., Vieira, S. N., Strüssmann, C., \& Mott, T. (2012). Contaminação de águas superficiais e de chuva por agrotóxicos em uma região do estado do mato Grosso. Ciência \& Saúde Coletiva, 17(6), 1557-1568. 10.1590/S1413-81232012000600019

Ministério da Saúde, (1992). Portaria $n^{o}$ 03, de 16 de janeiro de 1992 . Secretaria de Vigilância Sanitária. http://bvsms.saude.gov.br/bvs/saudelegis/svs1/1992/prt0003_16_01_1992.html

Ministério da Saúde, (2012). Portaria $n^{o}$ 2.938, de 20 de dezembro de 2012 . Secretaria de Vigilância Sanitária. http://bvsms.saude.gov.br/bvs/saudelegis/gm/2012/prt2938_20_12_2012.html

Ministério da Saúde, (2013). Orientações técnicas para o monitoramento de agrotóxicos na água para consumo humano.

Neto, M. de L. F., \& Sarcinelli, P. de N. (2004). Agrotóxicos em água para consumo humano: uma abordagem de avaliação de risco e contribuição ao processo de atualização da legislação brasileira. Revista Engenharia Sanitária e Ambiental, 14(1), 69-78.

Oliveira, L. K. de. (2016). O processo de poluição ambiental e alimentar por agrotóxicos em municípios da bacia do rio Juruena, Mato Grosso Luã. In Dissertação (mestrado). Universidade Federal de Mato Grosso.

OPAS, \& OMS. (1996). Manual de vigilância da saúde de populações expostas a agrotóxicos, (2a ed). Organização Pan-Americana da Saúde.

Palma, D. C. de A., \& Lourencetti, C. (2011). Agrotóxicos em Água e Alimentos: Risco à Saúde Humana. Revista Brasileira Multidisciplinar, 14(2), 15. 10.25061/2527-2675/rebram/2011.v14i2.108

Pereira Filho, J. (2013). Metodologia do Trabalho Científico: da teoria á prática. Gráfica e Editora Sanches Ltda. 
Peres, F., \& Moreira, J. C. (2003). É veneno ou é remédio? agrotóxicos, saúde e ambiente (FIOCRUZ (org.)).

Peters, F. T., \& Remane, D. (2012). Aspects of matrix effects in applications of liquid chromatography-mass spectrometry to forensic and clinical toxicology A review. Analytical and Bioanalytical Chemistry, 403(8), 2155-2172. 10.1007/s00216-012-6035-2

Pignati, W., Oliveira, N. P., \& Silva, A. M. C. da. (2014). Vigilância aos agrotóxicos: quantificação do uso e previsão de impactos na saúde-trabalho-ambiente para os municípios brasileiros. Ciência \& Saúde Coletiva, 19(12), 4669-4678. 10.1590/1413-812320141912.12762014

Ramos, H., Santos, J. M. F. dos, Araújo, R. M. de, Bonachela, T. M., \& Santiag, T. (2004). Manual de Tecnologia de Aplicação de Produtos Fitossanitários. ANDEF - associação Nacional de Defesa Vegetal, 52. 10.1029/2004JE002287

Revista Pazes. (2019). UFMG cria espuma que absorve agrotóxico da água e dos alimentos. https://www.revistapazes.com/ufmg-cria-espuma-que-absorveagrotoxico-da-agua-e-dos-alimentos/

Rissato, S. R., Libânio, M., Giafferis, G. P., \& Gerenutti, M. (2004). Determinação de pesticidas organoclorados em água de manancial, água potável e solo na região de Bauru (SP). Quimica Nova, 27(5), 739-743.

Santos, L. G. Dos. (2010). Avaliação da dispersão atmosférica e da deposição úmida de agrotóxicos em Lucas do Rio Verde, MT. Universidade Federal de Mato Grosso.

Secretaria de Vigilância em Saúde, S. (2016). Boletim Epidemiológico: Monitoramento de agrotóxicos em água pra consumo humano, Brasil, 2014. Ministério da Saúde, 47(12), 9. http://portalarquivos2.saude.gov.br/images/pdf/2016/marco/23/2015-052---Agrot--xicos-publica----o.pdf

Sidra, S. I. de R. A. (2019). Tabela 5457: Área plantada ou destinada à colheita, área colhida, quantidade produzida, rendimento médio e valor da produção das lavouras temporárias e permanentes. https://sidra.ibge.gov.br/tabela/5457\#resultado

Silva, C. M. M. de S., \& Fay, E. F. (2004). Agrotóxicos e Ambiente (Embrapa Informação Tecnológica (org.); (1ª ed). Embrapa Informação Tecnológica. https://doi.org/85-7383-282-7

Silva, T. V., \& De Queiroz, T. M. (2016). Agrotóxicos em mananciais superficiais no Assentamento Antônio Conselheiro, Mato Grosso. Revista IberoAmericana de Ciências Ambientais, 7(1), 235-243. 10.6008/spc2179-6858.2016.001.0020

Soares, A. F. S. (2011). Uso de agrotóxicos, contaminação de mananciais e análise da legislação pertinente [manuscrito] : um estudo na região de Manhuaçu MG. In Tese (Doutorado). Universidade Federal de Minas Gerais.

Soares, W. L., \& Porto, M. F. (2007). Atividade agrícola e externalidade ambiental: uma análise a partir do uso de agrotóxicos no cerrado brasileiro. Ciência \& Saúde Coletiva, 12(1), 131-143. 10.1590/s1413-81232007000100016

Trapé, A. Z. (1993). O caso dos agrotóxicos. In In: Rocha, et al. Isto é trabalho de gente?: vida, doença e trabalho no Brasil. (p. 568-593). 10.1590/s003471671994000100019

UE. (1998). Directiva 98/83/CE relativa à qualidade da água destinada ao consumo humano. Jornal Oficial das Comunidades Europeias, 332-354.

UFRGS Ciência. (2019). Com projeto para eliminar agrotóxico da água, estudantes buscam financiamento para participar da maior competição de biologia sintética do mundo - UFRGS Ciência. http://www.ufrgs.br/secom/ciencia/com-projeto-para-eliminar-agrotoxico-da-agua-estudantes-buscam-financiamentopara-participar-da-maior-competicao-de-biologia-sintetica-do-mundo/

Van Der Werf, H. M. G. (1996). Assesing the impact of pesticides on the environment. Agriculture, Ecosystems \& Environment, 60(2-3), 81-96. $10.1016 / \mathrm{S} 0167-8809(96) 01096-1$

Vieira, F. P., Fernandes, F. L., Gentil, F. H., Otávio, L., Silva, D., \& Ferreira, J. (2011). Histórico da aplicação de inseticidas para controle de pragas no Alto Paranaíba visando estudos de resistência de leucoptera coffeela (guérin-mèneville) (lepidoptera: lyonetiidae). VII Simpósio de Pesquisa dos Cafés do Brasil, 5. 